\title{
Obtaining of W/Cu nanocomposite powders by high energy ball milling process
}

\author{
Claudiu NICOLICESCU ${ }^{1, a^{*}}$, Victor Horia NICOARA ${ }^{2, b}$, Florin POPA ${ }^{3, c}$, Traian \\ Florin MARINCA ${ }^{4, d}$ \\ ${ }^{1,2}$ University of Craiova, Faculty of Mechanics, Department of Engineering and Management of \\ the Technological Systems, Drobeta-Turnu Severin, Romania \\ ${ }^{3,4}$ Technical University of Cluj-Napoca, Faculty of Materials and Environmental Engineering, \\ Department of Materials Science and Engineering, Technical University of Cluj-Napoca, Cluj- \\ Napoca, Romania \\ anicolicescu_claudiu@yahoo.com, ${ }^{b}$ victorczh@gmail.com, ${ }^{c}$ florin.popa@stm.utcluj.ro, \\ draian.marinca@stm.utcluj.ro
}

Keywords: Powder metallurgy, Tungsten nanopowders, W/Cu nanocomposite powders, Mechanical milling

\begin{abstract}
The morphology of the particles is important in the process of obtaining alloys based on $\mathrm{W} / \mathrm{Cu}$, thus this investigation is focused on the influence of the copper content on the properties of $\mathrm{W} / \mathrm{Cu}$ nanocomposites powders obtained after 20 hours of high energy ball milling. The experimental results regarding the obtaining of $\mathrm{W}_{100-\mathrm{x}} / \mathrm{Cu}_{\mathrm{x}}$ nanocomposites (x between 20 and 45 wt. \%) are presented. Composition of the mixtures influenced the particle size distribution namely, the higher is $\mathrm{Cu}$ content the larger dimensions of the particles will be attained. After 20 hours of high energy ball milling the crystallites size was about $30 \mathrm{~nm}$ for copper respectively $12 \mathrm{~nm}$ for tungsten and $\mathrm{Cu}$ atoms entered in the $\mathrm{W}$ structure.
\end{abstract}

\section{Introduction}

One of the specific classes of materials which are suitable for elaboration by Powder Metallurgy (PM) consists in pseudo-alloys based on $\mathrm{W}-\mathrm{Cu}$ due to their mutual insolubility. These materials are very important due to their wide field of applicability such as: welding electrodes, nozzle liners for rockets and missiles, heat sink materials, high power electrical contacts, fission reactors and so on, applications that require high mechanical properties conferred, in this case by tungsten, combined with high electrical and thermal conductivity which are conferred by copper [1-6]. The properties of these materials are in correlation with their composition and morphology and because of that is very important to choose the right composition function of the application [7]. In the field of high power electrical contacts, $\mathrm{W}$-Cu materials must have high arc erosion resistance high temperature strength and high tribological properties to ensure an as long as possible lifetime $[8,9]$. Particle size of the component elements plays an important role in the final properties of $\mathrm{W}$ $\mathrm{Cu}$ alloys [10]. One of the techniques used for fabrication of the $\mathrm{W}-\mathrm{Cu}$ materials is the infiltration one, which consists in the formation of a porous skeleton by tungsten which will be filled with molten copper. Vacuum pulse carburisation was reported [11] to be an infiltration method that leads to the formation of $\mathrm{W}-30 \mathrm{wt} . \% \mathrm{Cu}$ material with core-shell structure which presents high electrical conductivity (46.55\%IACS) compared to the national standard (GB/T8320-2003 $42 \%$ IACS) and a friction coefficient $\mu=0.64$. To improve the sinter ability of $\mathrm{W}$-Cu materials it can be introduced some activators such as $\mathrm{Ni}$, Fe or Co which can be grain growth inhibitors [12]. Using of this activators can lead to a decreasing of electrical and thermal conductivity of $\mathrm{W}-\mathrm{Cu}$ 
materials $[13,14]$.

A technique used for mass production which is suitable to produce $\mathrm{W}$-Cu complex shape parts is Metal Injection Moulding (MIM) [15].

Another method to produce W-Cu materials is Mechanical Alloying (MA) which ensures obtaining of the nanocomposite powders and structural homogeneity which leads to an improvement of the sintering process by reducing the sintering activation energy [16-19]. Compared with micron powders, by using submicron powders $(400 \mathrm{~nm})$ in the case of infiltrated $\mathrm{W}-25 \mathrm{wt} \% \mathrm{Cu}$ alloys can be obtained better properties such as: microstructural homogeneity, relative density (98.9\%), hardness (230 HB) [10]. By MA, in the case of W-Cu system, Cu phase can dissolute in the $\mathrm{W}$ phase [20]. In most of cases the MA process is carried out at room temperature [21, 22].

In the present work nanocomposite powders $\mathrm{W}_{100-\mathrm{x}} / \mathrm{Cu}_{\mathrm{x}}(\mathrm{x}=20-45 \mathrm{wt}$. \%) were prepared by mechanical milling (MM) process having as starting powders $\mathrm{W}$ nanometric and Cu micrometric powders. The influence of the MM times and composition of the mixture on the morphology, phase transformations and particle size distribution were investigated.

\section{Experimental work}

As raw materials were used tungsten nanopowders prepared by MM (35 hours of milling) and copper micrometric powders (type SE Pometon). The morphologies of the initial powders at the same magnification (1500x) are presented in (Fig. 1).
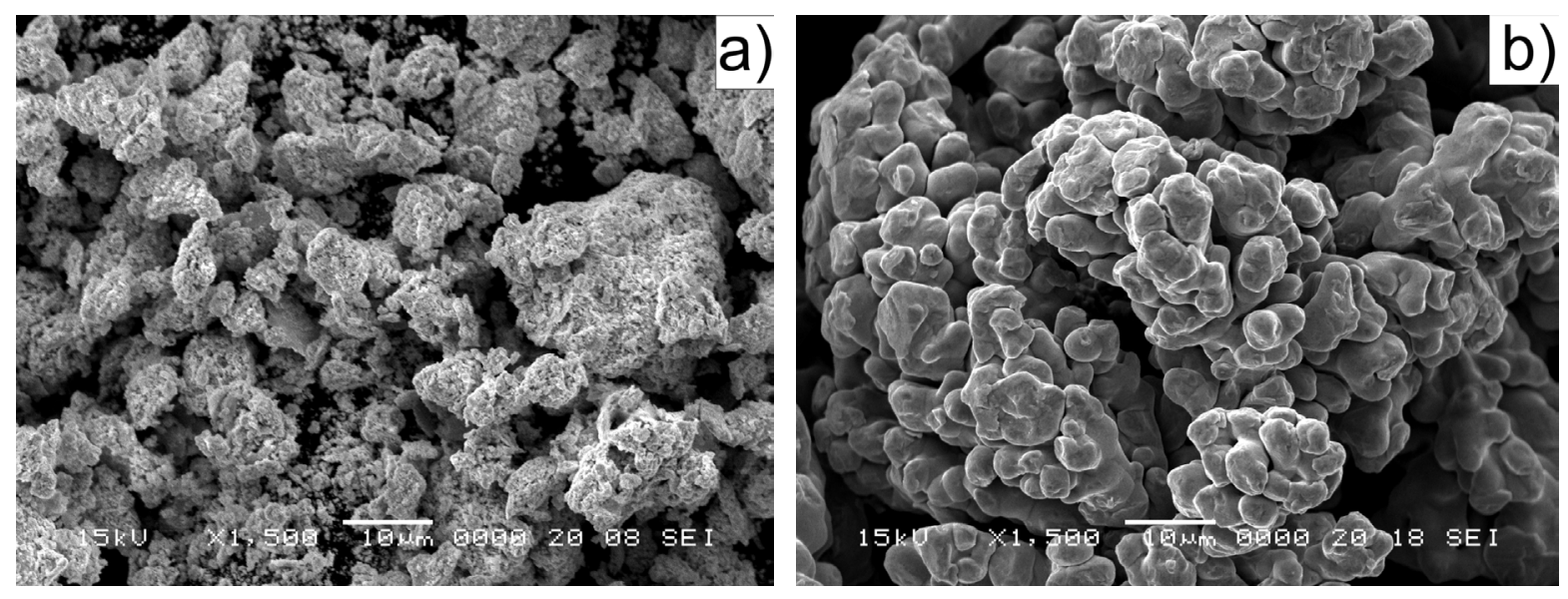

Fig. 1. SEM images of initial powders: a) W nanopowders; b) Cu powders.

For MM process of the six mixtures $\mathrm{W}_{100-\mathrm{x}} / \mathrm{Cu}_{\mathrm{x}}(\mathrm{x}=20,25,30,35,40,40$ and 45 wt. \%) a Pulverissete 4 Vario planetary ball mill made by Fritsch was used. The parameters used for MM were: bowls volume - $250 \mathrm{ml}$; material of the bowls - stainless steel; balls diameter - $10 \mathrm{~mm}$; balls material - stainless steel; milling type - dry; milling medium - argon (type 5.0, purity 99.999\%); material/ball weight ratio - 1/2; speed: $400 \mathrm{rpm}$ for the main disk and -800 rpm for the planets; milling time - 20 hours; from 5 to 5 hours were taken samples to be analysed.

In order to establish the cycles for MM, which means to not have higher temperature and pressure inside the grinding bowls, a GTM system made by Fritsch was used. In (Fig. 2) is presented the evolution of temperature and pressure for a MM of 10 minute with a break of 2 minutes. 


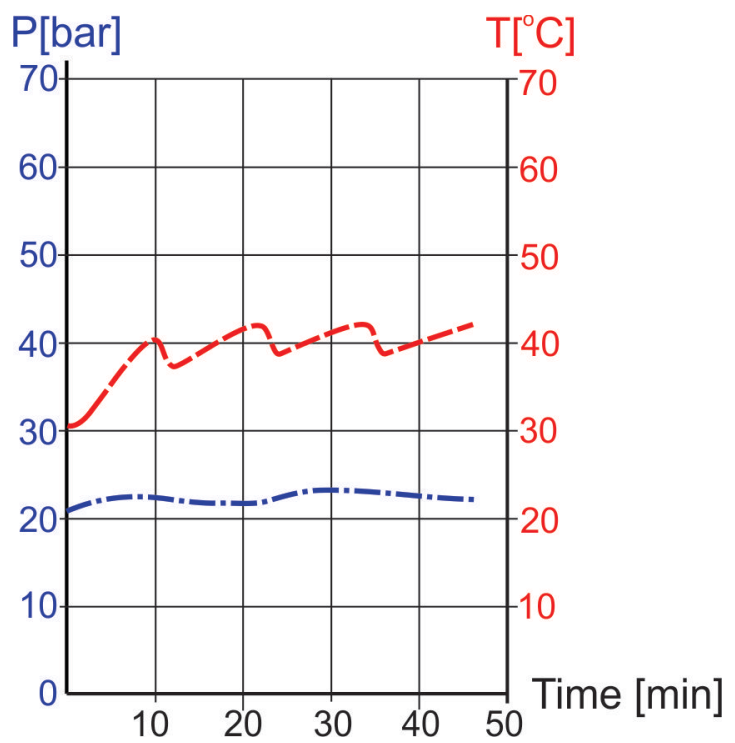

Fig. 2. Evolution of temperature and pressure inside the grinding bowl

As it can be seen in (Fig. 2), the temperature didn`t exceed $50{ }^{\circ} \mathrm{C}$ and the pressure is almost constant due to the dry milling type. These parameters must be controlled because if the temperature is higher, it can be damage the bowl and the equipment too.

For morphological aspects of the powder mixtures was used a JEOL microscope JSM-5600 LV.

Evolution of particle size distributions and polydispersity were studied by dynamic laser scattering (DLS) using a 90Plus particle size analyser, Brookhaven Instruments Corporation, USA, equipped with $35 \mathrm{~mW}$ solid state laser, having $660 \mathrm{~nm}$ wavelength. The temperature was 25 ${ }^{\circ} \mathrm{C}$ and the scattering angle was $90^{\circ}$. The dilutions of the powders mixtures were made in water and the solutions of each sample were subjected to ultrasonic treatment for 5 minutes to avoid flocculation of the particles.

The investigation by X-ray diffraction has been performed using an Inel diffractometer, model Equinox 3000 working in reflection and using Co radiation. The 2theta investigated interval was 20-110 degree.

\section{Results and discussion}

In (Fig. 3) are presented morphologies of the as initial homogenous mixture and for the samples milled for 20 hours, respectively. From (Fig. 3 a, c, e, g, i, k) it is obvious that the initial homogenised mixtures have tungsten particles with lower particle size (nanoscale) compared with those of copper. Also, in (Fig. $3 \mathrm{k}$ ) it is observed higher covering degree of tungsten nanopowders on the copper particles, which is in accordance with composition of the mixture $(80 \mathrm{~W} / \mathrm{Cu})$. After 20 hours of MM (Fig. 3 b, d, f, h, j, l) all the samples elemental individual morphology is changed to a homogenous state. Most probably a mixing and welding of different particles being realized. Also the powders tend to agglomerate.

Fig. 4 shows the XRD pattern of the mixtures in different stages. In the figure are presented the X-ray diffraction patterns of the W-Cu mixtures not milled samples and samples milled for 5, 10, 15 and $20 \mathrm{~h}$. Alongside of these patterns, in the same figure are presented the evolution of the mean crystallite size of the $\mathrm{W}$ and $\mathrm{Cu}$ upon increasing the milling time. In the X-ray diffraction patterns of the not milled samples on can observe the peaks characteristic for the $\mathrm{W}$ bcc structure 
from Im-3m space group and $\mathrm{Cu}$ fcc structure from Fm-3m space group according to JCPDS files 04-0806 and 04-0836 respectively.
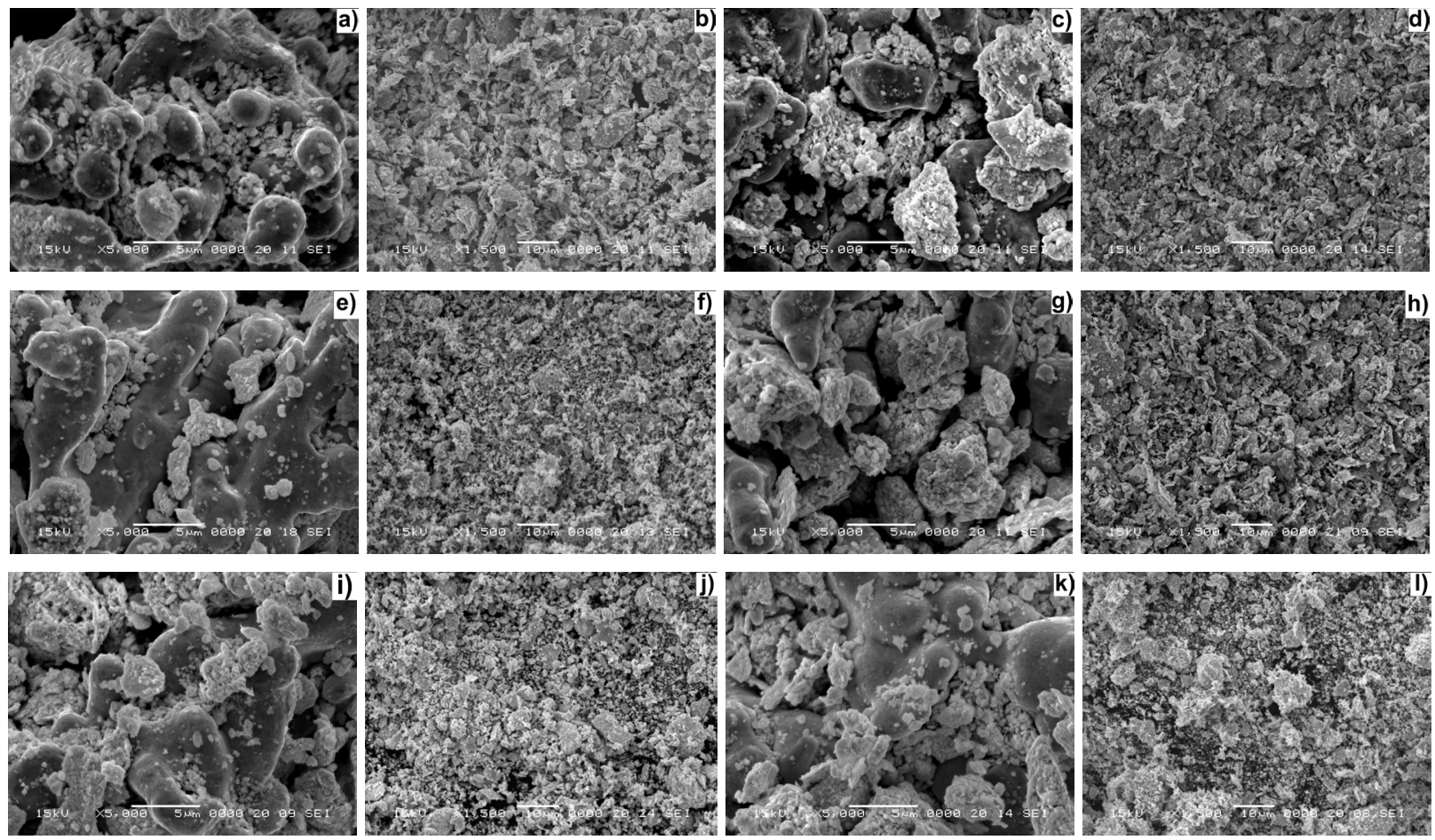

Fig. 3. SEM images of the: a) 55W/Cu homogenised mixture; b) 55W/Cu after 20 hours of MM; c) $60 \mathrm{~W} / \mathrm{Cu}$ homogenised mixture; d) $60 \mathrm{~W} / \mathrm{Cu}$ after 20 hours of MM; e) $65 \mathrm{~W} / \mathrm{Cu}$ homogenised mixture; f) 65W/Cu after 20 hours of MM; g) 70W/Cu homogenised mixture; h) 70W/Cu after 20 hours of $\mathrm{MM}$; i) 75W/Cu homogenised mixture; j) 75W/Cu after 20 hours of $\mathrm{MM}$; k) $80 \mathrm{~W} / \mathrm{Cu}$ homogenised mixture; l) 80W/Cu after 20 hours of MM;

The ratio of the $\mathrm{W}$ and $\mathrm{Cu}$ peaks intensities differ upon varying the amount of $\mathrm{W}$ and $\mathrm{Cu}$ in the mixtures, as expected. One can also observe is the broadening of the tungsten diffraction peaks due to the nanocrystalline state of the tungsten powder used in the mixture. The mean crystallite size of the tungsten powder (computed with the Scherrer method) is at $12 \pm 2 \mathrm{~nm}$. After $5 \mathrm{~h}$ of milling it can be noticed that the diffraction peaks of the copper are also broadened indicating the copper crystallite decreases. Further increase of the milling time lead also to the enlargement of the diffraction peaks of the copper and up to the final milling time no other peaks are identified in the diffraction patterns for all the ratios between $\mathrm{W}$ and $\mathrm{Cu}$. It can be observed that independent on the amount of $\mathrm{Cu}$ in the material its peaks are observed in the diffraction pattern. The fcc Cu-based structure is present in the material after $20 \mathrm{~h}$ of milling. Known that in equilibrium condition there is no solubility between $\mathrm{W}$ and $\mathrm{Cu}$ and known also that by mechanically milling solid solution between immiscible elements can be obtained, it can be assumed that after 20 of milling some $\mathrm{Cu}$ atoms entered in the $\mathrm{W}$ structure. At the end of milling time independent on $\mathrm{W}$ to $\mathrm{Cu}$ ratio according to X-ray investigation the material is a nanocomposite one consisting in a $\mathrm{W}$-Cu solid solution and $\mathrm{Cu}$ nanocrystallites. It can be remarked that the tungsten crystallites does not have significant variation upon milling together with copper. It remains at about $12 \pm 2 \mathrm{~nm}$. The mean 
crystallite size of the copper present a significant variation upon increasing the milling time. It can be noticed that during milling from 0 to $5 \mathrm{~h}$ a decrease from micrometer up to $65 \pm 2 \mathrm{~nm}$ occurs. Further increase of the milling time lead to a further refinement of the copper crystallites size up to $56 \pm 2 \mathrm{~nm}$ after $10 \mathrm{~h}$ of milling and reach $32 \pm 2 \mathrm{~nm}$ after $15 \mathrm{~h}$ of milling. At $20 \mathrm{~h}$ of milling the copper crystallite size is at about $30 \pm 2 \mathrm{~nm}$.
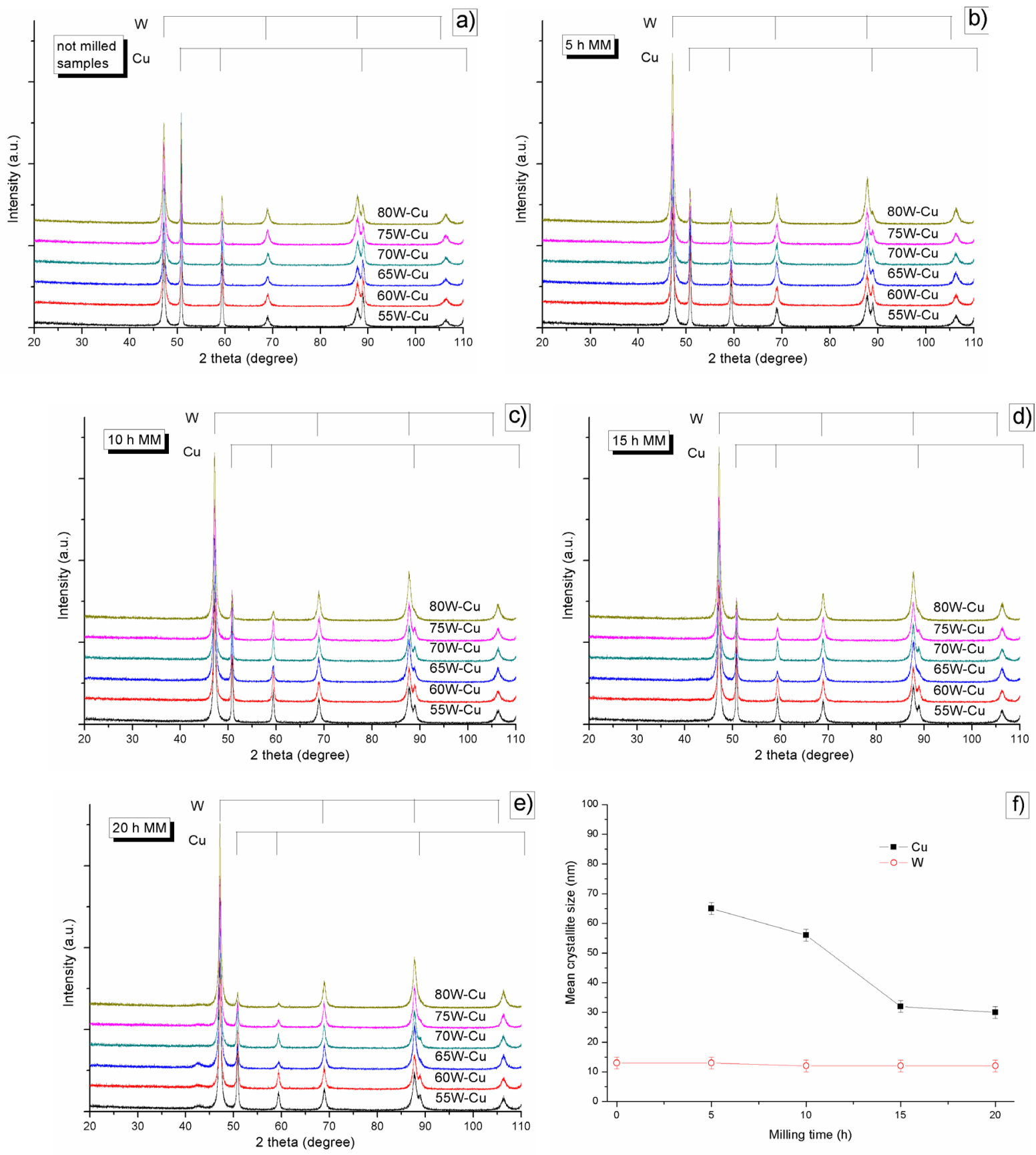

Fig. 4. X-ray diffraction patterns of the W-Cu mixtures: a) not milled - homogenised samples, b) samples milled for $5 \mathrm{~h}$, c) samples milled for $10 \mathrm{~h}$, d) samples milled for $15 \mathrm{~h}$, e) samples milled for $20 \mathrm{~h}$ and $\mathrm{f}$ ) evolution of the mean crystallite size of $\mathrm{W}$ and $\mathrm{Cu}$ upon milling 
In (Fig. 5) are presented the histograms of the number distribution versus particle size for all the mixtures after 20 hours of MM.
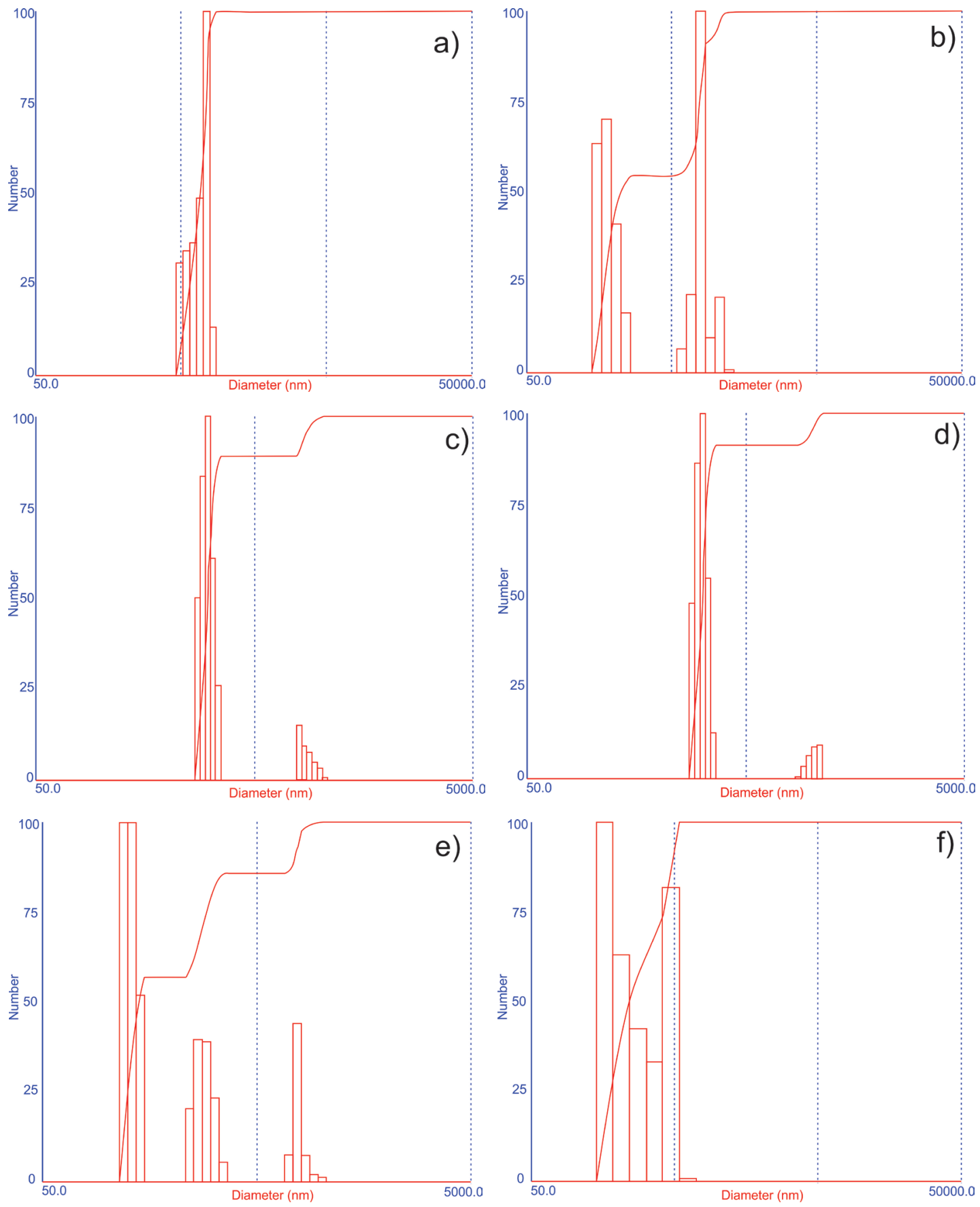

Fig. 5. Histograms of the particle size distributions of the mixtures after $20 \mathrm{~h}$ of $\mathrm{MM}$ : a) 55W/Cu;

b) $60 \mathrm{~W} / \mathrm{Cu}$; c) $65 \mathrm{~W} / \mathrm{Cu}$; d) $70 \mathrm{~W} / \mathrm{Cu}$; e) $75 \mathrm{~W} / \mathrm{Cu}$; f) $80 \mathrm{~W} / \mathrm{Cu}$;

In the case of $80 \mathrm{~W} / \mathrm{Cu}$, (Fig. $5 \mathrm{f}$ ), according to the DLS measurement the particles after $20 \mathrm{~h}$ of $\mathrm{MM}$ are in the range of (161-613) nm. The distribution presents the following structure: highest percent from the total number of the particles (31.15\%) is reported at $161 \mathrm{~nm} ; 16.63 \%-210 \mathrm{~nm}$; 13.08\% - 275; 10.28\% - $359 \mathrm{~nm} ; 25.55 \%$ - $469 \mathrm{~nm} ; 0.31 \%$ - $613 \mathrm{~nm}$. The presence of highest 
values of the distribution can be explained by the flocculation of these and to resolve this is better to find the proper time for ultrasonic treatment respectively to find anti flocculation agents in order to introduce them in the solution. For the mixture 75W/Cu, according to (Fig. 5 e) the particle size distribution presents three space-bars as following: one having small particles (119-143) nm, second between (243-346) $\mathrm{nm}$ and the third between (704-1004) nm. According to (Fig. $5 \mathrm{~d}$ ) the particle size distribution of the $70 \mathrm{~W} / \mathrm{Cu}$ is a bimodal one composed from small particles (262-353) $\mathrm{nm}$ and large particles (862-1077) $\mathrm{nm}$. The percent of the number for large particles is under $3 \%$. The mixture 65W/Cu, (Fig. 5 c), presents a bimodal particle size distribution with small particles $(275-340) \mathrm{nm}$ respectively large prticles $(800-991) \mathrm{nm}$. The large particles are under $5 \%$. In the case of $60 \mathrm{~W} / \mathrm{Cu}$, (Fig. 5 b) the DLS shows a bimodal particle size distribution with small particles $(152-238) \mathrm{nm}$ respectively large prticles (583-1232) $\mathrm{nm}$. The DLS analysis of the mixture $55 \mathrm{~W} / \mathrm{Cu}$, (Fig. 5 a) shows that the particles size is in the range of (488-821) $\mathrm{nm}$. Compared to the diameter of the particles from SEM analysis, the hydrodinamic diameter measured by DLS can be a little larger due to the fact that by DLS it is measured the diameter of a sphere which has the same average diffusion coeficient as the particle which is measured. According to Stokes-Einstein equation the hydrodynamic diameter is inversely proportional to the diffusion coefficient and it depends on the size of the particle core, its surface structure, concentration and type of ions in the medium [23, 24]. The polydispersity index decreases with particle size decreasing.

\section{Summary}

Based on the results it can be underline the following conclusions:

- Nanocomposite powders based on W/Cu were obtained after 20 hours of MM process having homogenous compositions, consist in W/Cu solid solution and nanocrystaline $\mathrm{Cu}$;

- Copper crystalite size decrease from micronic size in the initial homogenous mixture up to about $30 \pm 2 \mathrm{~nm}$ after 20 hours of MM. This process was very fast in the first 10 hours;

- The mixtures with higher concentration of $\mathrm{Cu}$ present larger particle size at each time of $\mathrm{MM}$;

By using these nanocomposite powders, according to [10] the sintering treatment can be improved leading to better properties of the final products.

\section{Acknowledgement}

This work was supported by the strategic grant POSDRU/159/1.5/S/133255, Project ID 133255 (2014), co-financed by the European Social Fund within the Sectorial Operational Program Human Resources Development 2007 - 2013.

\section{References}

[1] D.G. Kim, G.S. Kim, M.J. Suk, et al., Effect of heating rate on microstructural homogeneity of sintered W-15 wt\% Cu nanocomposite fabricated from W-CuO powder mixture, Scr. Mater. 51 (2004) 677-681. https://doi.org/10.1016/j.scriptamat.2004.06.014

[2] F.T.N. Vüllers, R. Spolenak, From solid solutions to fully phase separated interpenetrating networks in sputter deposited "immiscible” W-Cu thin films, Acta Mater. 99 (2015) 213-227. https://doi.org/10.1016/j.actamat.2015.07.050

[3] A. Elaayed, W. Li, O.A. El Kady, et al., Experimental investigations on the synthesis of W-Cu nanocomposite through spark plasma sintering, J. Alloys Compd. 639 (2015) 373-380. https://doi.org/10.1016/j.jallcom.2015.03.183 
[4] Q. Zhou, P.W. Chen, Fabrication of W-Cu composite by shock consolidation of Cu-coated W $\begin{array}{llllll}\text { powders, J. } & \text { Alloys } & \text { Compd. } & 657 & \text { (2016) }\end{array}$ https://doi.org/10.1016/j.jallcom.2015.10.057

[5] W.T. Qiu, Y. Pang, Z. Xiao, et al., Preparation of W-Cu alloy with high density and ultrafine grains by mechanical alloying and high pressure sintering, Int. J. Refract. Met. Hard Mater. 61 (2016) 91-97. https://doi.org/10.1016/j.ijrmhm.2016.07.013

[6] S.H. Liang, L. Chen, Z.X. Yuan, et al., Infiltrated W-Cu composites with combined architecture of hierarchical particulate tungsten and tungsten fibers, Mater. Charact. 110 (2015) 33-38. https://doi.org/10.1016/j.matchar.2015.10.010

[7] Y. Yu, W. Zhang, H. Yu, Effect of $\mathrm{Cu}$ content and heat treatment on the properties and microstructure of $\mathrm{W}-\mathrm{Cu}$ composites produced by hot extrusion with steel cup, Adv. Powder Technol. 26 (2015) 1047-1052. https://doi.org/10.1016/j.apt.2015.04.012

[8] C. Ding, X.C. Yuan, Z.B. Li, et al., Contact erosion characteristics in making process of SF6 circuit breakers, High Volt. Eng. 40 (2014) 3228-3232.

[9] Q. Zhang, X.H. Yang, B.Y. Liu, et al., Failure analysis of capacitor bank switch arcing contact for ultra-high voltage system, High Volt. Appar. 52 (2016) 27-32.

[10] Q. Zhang, S.H. Liang, B.Q. Hou, et al., The effect of submicron-sized initial tungsten powders on microstructure and properties of infiltrated W-25 wt\% Cu alloys, Int. J. Refract. Met. Hard Mater. 59 (2016) 87-92. https://doi.org/10.1016/j.ijrmhm.2016.05.014

[11] Q. Zhang, S. Liang, L. Zhuo, Fabrication and properties of the $\mathrm{W}-30 \mathrm{wt} \% \mathrm{Cu}$ gradient composite with W@WC core-shell structure, Journal of Alloys and Compounds, 708 (2017) 796-803. https://doi.org/10.1016/j.jallcom.2017.03.064

[12] J. Johnson, R. German, Phase equilibria effects on the enhanced liquid phase sintering of tungsten-copper, Metall. $\quad$ Trans. $\quad$ A. $24 \quad$ (1993) 2369-2377. https://doi.org/10.1007/BF02646516

[13] S.H. Hong, B.K. Kim, Fabrication of W-20 wt.\% Cu composite nanopowder and sintered alloy with high thermal conductivity, Mater. Lett. 57 (2003) 2761-2767. https://doi.org/10.1016/S0167-577X(03)00071-5

[14] P. Chen, Q. Shen, G. Luo, M. Li, L. Zhang, Themechanical properties of W-Cu composite by activated sintering, Int. J. Refract. Met. Hard Mater. 36 (2013) 220-224. https://doi.org/10.1016/j.ijrmhm.2012.09.001

[15] Ijaz Ul Mohsin, Christian Gierl, Herbert Danninger, Sintering study of injection molded W$8 \% \mathrm{Ni}-2 \% \mathrm{Cu}$ compacts from mixed powders by thermoanalytical techniques, Int. Journal of Refractory Metals and Hard Materials, 29 (2011) 532-537. https://doi.org/10.1016/j.ijrmhm.2011.03.006

[16] J.S. Lee, T.H. Kim, Densification and microstructure of the nanocomposite W-Cu powders, Nanostruct. Mater. 6 (1995) 691-694. https://doi.org/10.1016/0965-9773(95)00152-2

[17] L.J. Kecskes, M.D. Trexler, B.R. Klotz, K.C. Cho, R.J. Dowding, Densification and structural change of mechanically alloyed W-Cu composites, Metall. Mater. Trans. A. 32A (2001) 2885-2893. https://doi.org/10.1007/s11661-001-1039-0

[18] F.A. Costa, A.G. Silva, U.U. Gomes, The influence of the dispersion technique on the characteristics of the $\mathrm{W}-\mathrm{Cu}$ powders and on the sintering behavior, Powder Technol. 134 (2003) 123-132. https://doi.org/10.1016/S0032-5910(03)00123-2 
[19] M.H. Maneshian, A. Simchi, Z.R. Hesabi, Structural changes during synthesizing of nanostructured W-20 wt\% Cu composite powder by mechanical alloying, Mater. Sci. Eng. A. 445-446 (2007) 86-93. https://doi.org/10.1016/j.msea.2006.09.005

[20] S.N. Alam, Synthesis and characterization of $\mathrm{W}-\mathrm{Cu}$ nanocomposites developed by mechanical alloying, Materials Science and Engineering A 433 (2006) 161-168. https://doi.org/10.1016/j.msea.2006.06.049

[21] B.S. Murty, S. Ranganathan, Novel materials synthesis by mechanical alloying/milling, Int. Mater. Rev. 43 (1998) 101-141. https://doi.org/10.1179/imr.1998.43.3.101

[22] T.R. Malow, C.C. Koch, Mechanical properties in tension of mechanically attrited nanocrystalline iron by the use of the miniaturized disk bend test, Acta Mater. 46(18) (1998) 6459-6473. https://doi.org/10.1016/S1359-6454(98)00294-8

[23] M. Lungu, V. Tsakiris, E. Enescu, et al., Development of W-Cu-Ni Electrical Contact Materials with Enhanced Mechanical Properties by Spark Plasma Sintering Process Acta Physica Polonica A, 125 (2014) 327-330.

[24] M. Kaszuba, D. McKnight, M.T. Connah, et al., Measuring sub nanometre sizes using dynamic light scattering, J. Nanopart. Res. 10 (2008) 823. https://doi.org/10.1007/s11051007-9317-4 